MANAGEMENT, MARKETING, ECONOMIC INFORMATICS AND CYBERNETICS

\title{
INTEGRATED REPORTING AND PERFORMANCE. A BIBLIOMETRIC ANALYSIS
}

\author{
Bianca Baditoiu ${ }^{1}$, Munteanu Valentin Partenie ${ }^{2}$, Buglea Alexandru ${ }^{3}$ \\ 1 West University of Timișoara, Doctoral School of Economics and Business \\ Administration, \\ 2 West University of Timișoara, Faculty of Economics and Business Administration, \\ Management Department, \\ ${ }^{3}$ West University of Timișoara, Faculty of Economics and Business Administration, \\ Management Department, \\ bianca.baditoiu@e-uvt.ro \\ valentin.munteanu@e-uvt.ro \\ alexandru.buglea@e-uvt.ro
}

\begin{abstract}
This paper consists of an analysis of scientific works with respect to the subject of integrated reporting and its connection with the performance topic. Integrated reporting, implemented by the International Integrated Reporting Council, represents a strategic communication regarding various resources of the organizations, their relationship with all stakeholders and their capitals (financial, manufactured, intellectual, human, social and relationship, and natural capital) created over time. This new form of reporting is adopted by different organizations in many countries nowadays, yet there are some inconsistencies, especially in terms of insufficient clarification of the concept, both conceptually and procedurally (regarding the adoption of the International Framework), as well as the opportunities and real benefits of its implementation. As the number of studies on integrated reporting in the last decade also substantially increased, while many evidences find themselves in conflict, it raises the need to highlight the main common subjects related to this theme. Thus, by means of bibliometric analysis, this study qualitatively analyses 262 references from the Web of Science (WoS) Core Collection Database, while addressing the research tools provided by the VOSviewer similarities visualization program and screening the existing specialty literature. The focus of the study is on co-occurrence of keywords, coauthorship and co-citation in the research field of integrated reporting and its performance and it reflects the most common concepts associated with these terms and the authors, organizations and countries that researched these themes. The results of the study revealed the large areas in which integrated reporting exerts its influence and the implications in both the social and the economic sphere, while highlighting the need of a long term organizational change with this respect.
\end{abstract}

Keywords: Integrated Reporting; Performance; Bibliometric Analysis; Visualization.

JEL Classification: M14; M49; 016.

\section{Introduction}

Over the past decade, the number of integrated reporting (IR) adopters has substantially increased, with the aim of companies of focusing not solely on financial reporting, but also non-financial aspects, trying to align the firms' activities with the shifting societal and regulatory expectations, which gained more and more importance every day worldwide. The decision of publishing such reports is voluntary in most jurisdictions, except in South Africa, where listed companies on the Johannesburg Stock Exchange are mandated with this 
respect. However, the adoption of integrated reporting can benefit most companies, according to some authors, while enhancing their corporate reputation through superior accountability and transparency (Oliviera, Rodrigues and Craig, 2019; Suttipun, 2017). Different perceptions state that by comparison, business organisations that conduct in substantial negative external impact tend to offer more detailed integrated reports than those with insignificant environmental consequences, in order to shed legitimacy on their business (Buitendag, Fortuin and De Laan, 2017). In this sens, the information disclosure could therefore be used in an attempt to 'repair' poor legitimacy (Suchman, 1995) and could be symbolic rather than substantive (Malola and Maroun, 2019). In opposition, Lopes and Coehlo (2018) suggested that there is a greater probability for business organizations with a high level of integrated reporting quality to be large, profitable and less leveraged.

Integrated reports have been described by the International Integrated Reporting Council (IIRC) as precise “communications about how an organization's strategy, governance, performance and prospects, in the context of its external environment, lead to the creation of value over the short, medium and long term" (IIRC, 2013, p. 8). While taking into account this aspects, integrated reports provides both financial and non-financial information for all stakeholders involved. IIRC associated integrated reporting with the term "integrated thinking" while describing it as "the active consideration by an organization of the relationships between its various operating and functional units and the capitals that the organization uses or affects" (IIRC, 2013, p. 3). This integrated thinking can foster numerous integrated decision-making and actions that focuses on the creation of value over the short, medium and long term of a company. This holistic approach emphasizes the value creation for companies, therefore being many times associated with performance over time. However, there are also many conflicting evidences in the specialty literature that address issues such as different prospects (Adhariani and de Viliers, 2018), challenges (De Villiers, Rinaldi and Unerman, 2014; McNally, Cerbone and Maroun, 2017), and implications (Dumay et al., 2017; Iredele, 2019) of the implementation and adoption of integrated reporting.

Therefore, of particular significance for this study are recent articles, which study the concept of integrated reporting, while linking it with the subject of performance, detailed in the next section.

The present paper is structured as follows. Theoretical framework addresses the principal concept and the specialty literature regarding integrated reporting in terms of its connectivity with the performance theme. Next, the paper detailed the collected data and methodology used (Methodology). The fourth part (Results) offers details about the main results of the study. Lastly, the study presents a discussion of the findings and the concluding observations, while pointing out also the research limits and the associated potentially forthcoming research directions.

\section{Theoretical framework}

Integrated reporting is acquiring more and more interest from the research community, corporate and investor communities as well as practitioners and policy makers. Different studies with respect to the connection between integrated reporting and either financial, environmental, operational or market performance reflect also many disagreeing evidences. Buallay, Hawaj and Hamdan studied in 2020 the relationship between the disclosure of integrated reporting and Islamic and conventional banks performance (financial, operational and market) and provides perspective while demonstrating that IR positively affects market performance, while negatively affecting operational and financial performance in the case of conventional banks. Their descriptive analysis highlights that $73 \%$ of the banks represent integrated reporting adopters. The authors also highlighted that integrated reporting 
negatively influences market performance of Islamic banks, with no obvious effect on neither financial nor operational performance. In their analysed banking sector, namely the Gulf Cooperative Council (GCC), the bank performance would not improve where integrated reports are mandated, this statement being stronger when regarding Islamic bank than with respect to conventional banks in the region (Buallay, Hawaj and Hamdan, 2020). Omran, Zaid and Dwekat (2021) investigate the link between integrated reporting and corporate environmental performance. A sample of 110 firms where integrated reporting was first mandated, listed on the Johannesburg Stock exchange for the years 2014-2018 made the object of their study. Their empirical results are plentiful and in compliance with our predictions regarding the positive association between integrated reporting and corporate environmental performance. Furthermore, there is evidence suggesting that compliance with the current established framework permits IR to act as an instigating instrument in the process of corporate environmental change. Their study thus concludes that high-quality integrated reporting is quite probably part of the behaviour of global environmentally responsible businesses. The authors provide evidence that supports the position of IR in aligning the firm's central values with their corporate reporting with respect to the environment. Their results indicate also that qualitative integrated reporting practices are unlikely to have symbolic value but rather, part of general environmentally responsible corporate strategies, additional supporting the idea that high quality IR can be effective in terms of the transformation function. Matemane and Wentzel (2019) conducted one of the few sector-specific studies and investigate the presence or absence of a correlation between IR and performance, while examining the relationship between IR quality and bank performance, for the case of South African Banks, in the period 2010-2014, focusing on secondary data, comparing them to the pre-IR implementation period. No statistically significant relationship was proved to exist between IR quality and bank performance according to Tobin's Q (TQ) ROA, ROE.

A similar topic, corporate sustainability disclosure was also examined with respect to its impact on the performance of companies (growth in bank deposits), by analysing public conventional and Islamic banks from the United Arab Emirates (UAE) (Nobanee and Ellili, 2016). With respect to the integrated reporting quality (IRQ), Barth et al (2017) reported a significant, positive relationship between IRQ and organizational value, largely attributed to liquidity and expected future cash flows rather than on cost capital, by using reporting measures based on twelve components, according to the IIRC framework principles and content elements.

Thus, the financial performance and integrated reporting quality (IRQ) have also a contrasting relationship in many researched articles. Some researchers find positive associations between IRQ and organizational value (Lee and Yeo, 2016), while others emphasized the absence of significant evidence, linking IRQ with organizational value (Buitendag, Fortuin and De Laan, 2017; Horn, De Klerk and De Villiers, 2018; Marcia, Maroun and Callaghan, 2015) and with profitability (Buitendag, Fortuin and De Laan, 2017). The conclusion of this section is in agreement with De Viliers, Hsiao and Maroun (2017), in that shareholders are encouraged to implement a long-term investment focus, sustaining that they should pressurize organizations to be more transparent, to prove more decisionusefulness and accountability relating to the six capitals instead of simply concentrating on financial capital.

\section{Methodology}

Web of Science Core Collection, one of the most popular database, is an online bibliographic and bibliometric database, comprising mainly scientific journals, conferences and books of high quality. Consequently, based on a sample of 262 references selected 
from the Web of Science (WoS) Core Collection database, including mostly articles, proceedings papers and book chapters, from 1999 to 2021, a bibliometric analysis is conducted, while associating the "integrated reporting" concept with the "performance" concept. Data on the most common keywords, journals, authors and citations are first collected, than verified, validated and interpreted, while applying bibliometric measures by means of science mapping through the VOSviewer software. VOSviewer is a software instrument for creating and picturing bibliometric networks. These networks can for example consist of journals, researchers, or individual scientific publications and they can be ultimately shaped grounded on citation, bibliographic coupling, co-citation, or co-authorship relations.

Regarding the main focus of this paper, the sample was obtained using the topic based search of two keywords, mentioned above as concepts, namely: "integrated reporting" and "performance".

This paper observed the keywords that arise in the analyzed documents (co-occurrence of keywords), the co-citation (cited authors) and co-authorship (regarding both countries and organizations/institutions) within the sample of 262 documents. The results are presented in the next section.

\section{Results and interpretation}

\subsection{Keywords Co-occurrence Analysis}

First, regarding the keyword analysis through this type of method, the most persistent keywords were highlighted in Figure 1 (processed using VOSviewer), by means of analysing a minimum of five simultaneously-occurring keywords in each of the analysed articles (minimum number of occurrences of a keyword=5). All types of keywords are taken into account for this purpose, in order to highlight the most relevant ones in the field of integrated reporting and the overall general performance that can be generated. Figure 1 presents the most relevant keywords and the links between them in compliance with the following rule: the larger the keyword and the link, the larger the weight. The common clusters of keywords and the related keywords are indicated with the same colour. There are five clusters, as follows. The first cluster (red) is build out of 39 items, led by the keyword with the second highest occurrences, which represents one of the focus of the papers theme, namely "performance", along with other important keywords, such as "disclosure", "information" and "governance. The second cluster, represented by the green colour, is build out of 30 items, led by the "integrated reporting" keyword, highlighting both the highest number of links (119) and the highest total link strength of 161 , while representing also the research topic. The following most significant keywords for the second cluster are: "management", "insights" and "integrated thinking". The third cluster (blue) comprises 23 items, among which the most frequent keywords are "sustainability", "corporate social responsibility", "sustainability reporting", "financial performance" and "impact". The yellow colour represents the forth cluster, including 17 items, among which the most relevant ones are the followings: "determinants", "assurance", "content analysis" and "market". Finally, the fifth cluster (mauve), containing 12 items is led by the "disclosures" keyword, followed by "South Africa" and "strategy".

The most common keyword refers to "integrated reporting", followed in this rank by "performance" and "sustainability", while the least common keyword refers to "diversity", followed by "disclosure quality".

The short distance between both the second (green) and the third cluster (blue) and the first (red) and the third cluster (blue), highlights the strong connection between integrated reporting and sustainability as well as the one between integrated reporting and performance. 


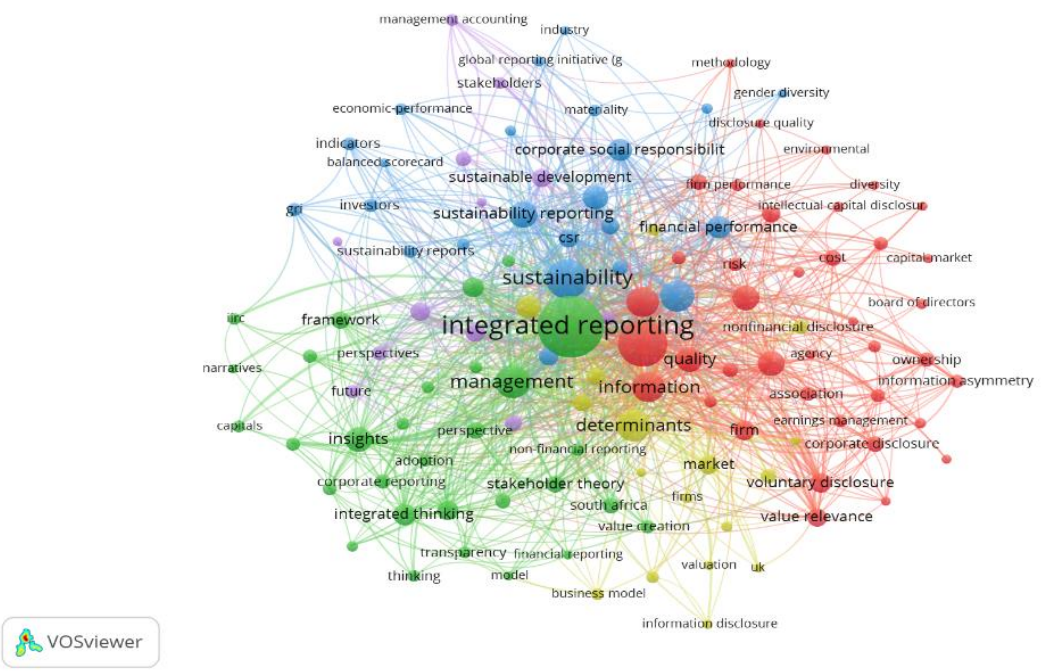

Figure 1: Co-occurrence network of all keywords within integrated reporting publications Source: original

\subsection{Cited Authors Co-citation Analysis}

The network of the main authors who studied this topic was analysed in this section, at the same time highlighting the researchers who proved to be more preoccupied by the matter. Although we analysed an emerging topic, the threshold of the minimum number of citations of an author was set on 20 and out of 6749 authors, 98 met this threshold. Thus, Figure 2 (processed using VOSviewer) highlights the 4 resulting clusters. The first cluster, represented by the red colour, comprises 31 items, De Villiers being the most cited author, with 204 citations and 190 total link strength, followed by Adams, with 167 citations, IIRC (144 citations) and Dumay (143 citations). The second cluster, represented by the green colour, includes 27 authors and is led by Frias-Aceituno and International Integrated Reporting Council (IIRC), both with 121 citations, followed by Garcia-Sanches with 75 citations. Regarding the citation perspective, the blue cluster (third cluster) can be considered the main cluster for this research part. This cluster contains 21 items and is represented by Eccles, the author with the highest number of citations, namely 217 . The last cluster (yellow) includes 19 authors and is led by Gray (99 citations), followed by Deegan (97 citations) and Guthrie (87 citations).

Finally, it can be mentioned that there are numerous authors who address the issues of integrated reporting and performance. 


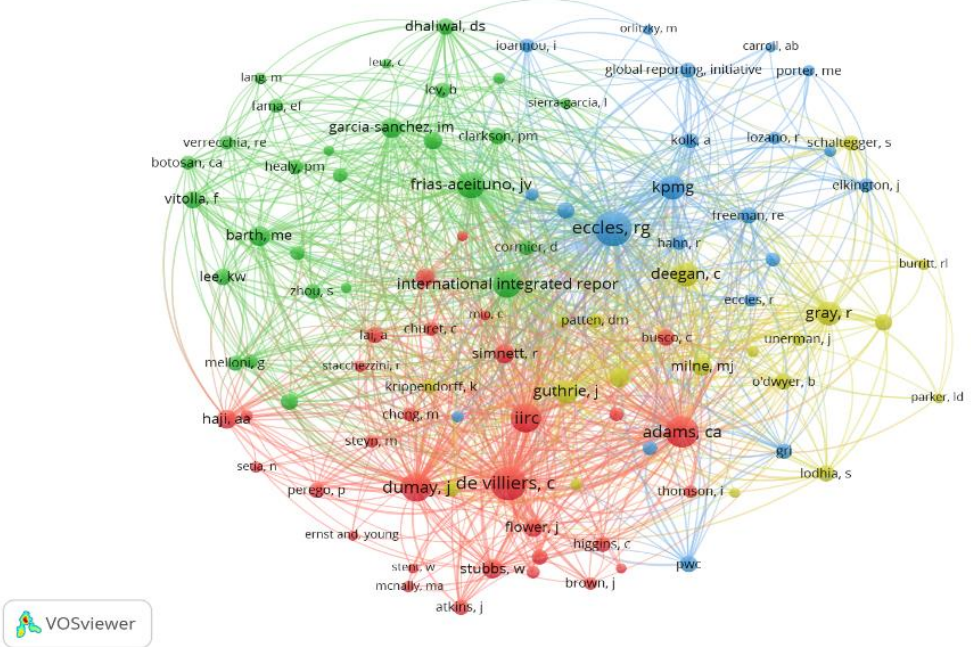

Figure 2: Co-citation of authors researching the integrated reporting and performance topics

Source: original

\subsection{Countries and Organizations Co-Authorship Analysis}

This type of method permits analysing the relatedness of items based on the number of coauthored documents. Therefore, the nodes represents in this case either the involved countries or the contributing organizations/institutions, while the thickness and the distance between them reflects the degree of their collaboration/cooperation/association.

This section comprises two co-authorship analyses, the first focusing on the countries and the second regarding the organizations.

Regarding the countries co-authorship analysis, the threshold of the minimum number of documents of a country, was set to 5 , and out of the 57 countries, only 17 met this threshold. Figure 3 (processed using VOSviewer) presents the nodes and the links between them, while highlighting the presence of 5 clusters, represented by different colours. The first cluster (red) includes 5 countries: Germany (with 18 documents), followed by Spain with 13 documents, France (10 documents), and Switzerland and the Netherlands, both with only 6 documents. The second cluster (green) contains only 4 countries, which are led by the USA with 24 documents, followed by Australia with 19 documents, Turkey (8 documents) and Russia ( 6 documents). The next cluster is the blue one, containing only 2 countries, however representing also the main cluster for this research part, because of the presence of the country with the highest number of documents- Italy (49 documents). The second country in this cluster is Romania, positioning itself on the third position in this ranking, with 23 documents. The yellow cluster (cluster 4) contains also 2 countries: England (with 23 documents) and Scotland (with 5 documents). South Africa with 23 documents and New Zeeland find themselves surprisingly in the fifth cluster (mauve), although South Africa is a country where integrated reporting is actually mandatory for the Johannesburg Stock Exchange listed companies. 


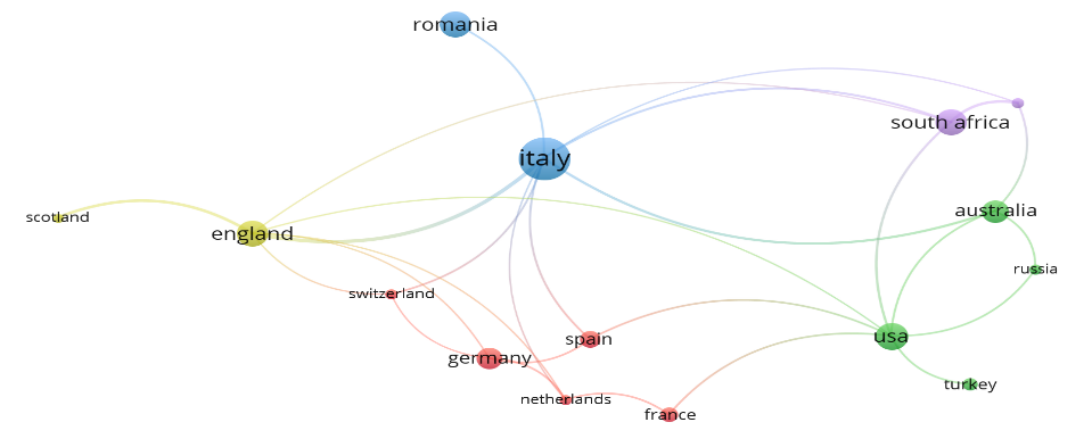

\section{S Vosviewer}

Figure 3: Countries Co-authorship

Source: original

The last study of this paper consists of the analysis of organizations/institutions coauthorship, by setting the threshold to a minimum number of 4 documents of an organization. The results are presented in the following Figure (Figure 4- processed using VOSviewer). Remarkably, out of 335 organizations, only 10 met this threshold, indicating the particularity and novelty of the research topic, while highlighting only the nodes for the significant ones with this respect. The study resulted in 9 clusters with 10 items (universities). With respect to the analysed topics, the Bucharest University of Economics Studies, with 14 documents, represents unexpectedly the most important university, outranking the universities from Africa from this perspective. Next in this ranking, follows University of Pretoria, University of Salamanca and University Witwatersrand of Johannesburg (each with 6 documents), the University of Auckland, Bocconi University, Macquarie University (Australia) and University of Milano-Bicocca (each with 5 documents). At the bottom of this ranking are RMIT University (China) and University of Stellenbosch (South- Africa), each with 4 documents. The missing links between the represented nodes could also be related to the long geographical distance between the universities and to the university field of study.

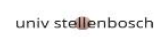

\section{B vosviewer boccoli univ}

Figure 4: Organizations Co-authorship

Source: original 


\section{Discussion and Conclusion}

Even though a similar study regarding the bibliographic analysis of integrated reporting has been conducted by Di Vaio et al. in 2020, the connection with the performance topic has not been addressed yet. Thus, through the executed analysis, it can be concluded first that a significant number of keywords relevant for the current analysed topics was observed. A visualisation of the most frequent and significant keywords is presented in Figure 1, while the most significant are the following ones: "integrated reporting", "performance" and "sustainability". Subsequent to this analysis, it can be stated that integrated reporting is strongly connected with "sustainability" and "sustainable development", "performance", "quality", "information", "management" and many other connected subjects. Next, through co-citation analysis, the most important authors in the research area were highlighted (Figure 2). Last, but not least, the co-authorship analyses emphasised the countries and organizations/institutions (universities) with the highest number of documents regarding this research area.

Studies conducted in countries with mandatory IR reveal that disclosure through this type of reporting does not only increase firm effectiveness and efficiency but it also nurtures the achievements of a business organization's objectives and mission. Thus, integrated reporting can be used both as an "influential" tool for corporate disclosure and as an important component in an integrated marketing communications plan. This is the reason why the analysis of the links between the two investigated topics is relevant.

After a decade from the introduction of IR as defined by the IIRC, South Africa constitutes a proper research field in order to explore the level to which this combined form of reporting (financial and non-financial reporting) thrives in establishing relationships between IRQ, environmental/sustainability performance and financial performance, this aspect being also highlighted through this papers' keyword analysis.

As a general conclusion, despite the fact that the economic consequences of IR in South Africa have been a subject of focus for several authors, taking into consideration the country's front-runner status regarding IR, South Africa is unexpectedly not the country where the maximum record of authors approaching this research theme was found. Instead, Italy comprises the largest number of documents, while the Bucharest University of Economic Studies (from Romania), with 14 documents is at the top of the rank with respect to institutions.

Content analysis of integrated reports continues to require improvement even after 10 years of experimenting with the IIRC framework. It should go further than simply considering the length of disclosures and compliance with core content elements and aim for closer examinations of reporting quality and applying the IIRC's principles (comprising strategic focus, materiality and conciseness).

The novelty of the researched topic and the relatively few integrated reporting adopters can be regarded as limitations of this paper, resulting in only 262 references, a quite small database when referring to bibliometric analysis.

Future research should focus on studying the interaction between IR and integrated thinking and the connection between the two concepts or the link between IR and its principles, founded by IIRC.

\section{References}

1. Adhariani, D. and de Villiers, C. (2018) 'Integrated reporting: perspectives of corporate report preparers and other stakeholders', Sustainability Accouning, Management and Policy Journal, 10(1), 126-156. 
2. Barth, M.E., Cahan, S.F., Chen, L. and Venter, E.R. (2017) 'The economic consequences associated with integrated report quality: Capital markets and real effects', Accounting, Organizations and Society, 62(1), 43-64.

3. Buallay, A., Al Hawaj, A.A. and Hamdan, A. (2020) 'Integrated reporting and performance: a crosscountry comparison of GCC Islamic and conventional banks', Journal of Islamic Marketing, Vol. ahead-of-print No. ahead-of-print.

4. Buitendag, N., Fortuin, G.S. and De Laan, A. (2017) 'Firm characteristics and excellence in integrated reporting', South African Journal of Economic and Management Sciences, 20(1), a1307.

5. De Villiers, C., Hsiao, P-C.K. and Maroun, W. (2017) 'Developing a conceptual model of influences around integrated reporting, new insights and directions for future research', Meditari Accountancy Research, 25(4), 450-460.

6. De Villiers, C., Rinaldi, L. and Unerman, J. (2014) 'Integrated reporting: insights, gaps and an agenda for future research', Accounting, Auditing \& Accountability Journal, 27(7), 1042-1067.

7. Di Vaio, A., Syriopoulos, T., Alvino, F. and Palladino, R. (2020) "Integrated thinking and reporting" towards sustainable business models: A concise bibliometric analysis'. Meditari Account. Res., Vol. ahead-of-print No. ahead-of-print.

8. Dumay, J., Bernardi, C., Guthrie, J. and La Torre, M. (2017) 'Barriers to implementing the International Integrated Reporting Framework: A contemporary academic perspective', Meditari Accountancy Research, 25(4), 461-480.

9. Horn, R., De Klerk, M. and De Villiers, C. (2018) 'The association between corporate social responsibility reporting and firm value for South African firms', South African Journal of Economic and Management Sciences, 21(1), a2236.

10. Iredele, O. O. (2019) 'Examining the association between quality of integrated reports and corporate characteristics', Heliyon, 5(7), e01932.

Lee, K-W. and Yeo, G.H-H. (2016) 'The association between integrated reporting and firm value', Review of Quantitative Finance and Accounting, 47(4), 1221-1250.

11. Lopes, A.I. and Coelho, A.M. (2018) 'Engaged in integrated reporting? Evidence across multiple organizations', European Business Review, 30(4), 398-426.

12. Malola, A. and Maroun, W. (2019) 'The measurement and potential drivers of integrated report quality: Evidence from a pioneer in integrated reporting', South African Journal of Accounting Research, 33(2), 114-144.

13. Marcia, A., Maroun, W. and Callaghan, C., 2015, 'Value relevance and corporate responsibility reporting in the South African context: An alternate view post King-III', South African Journal of Economic and Management Sciences, 18(4), a1192.

14. Matemane, R. and Wentzel, R. (2019) 'Integrated reporting and financial performance of South African listed banks', Banks and Bank Systems, 14(2), 128-139.

15. McNally, M. A., Cerbone, D. and Maroun, W. (2017) 'Exploring the challenges of preparing an integrated report' [Abstract], Meditari Accountancy Research, 25(4), 481-504.

16. Nobanee, H. and Ellili, N. (2016) 'Corporate sustainability disclosure in annual reports: evidence from UAE banks: Islamic versus conventional', Renewable and Sustainable Energy Reviews, Vol. 55, 1336-1341.

17. Oliviera, L., Rodrigues, L.L. and Craig, R. (2019) 'Intellectual capital reporting in sustainability reports', Journal of Intellectual Capital, 11(4), 575-594.

18. Omran M.S.Y., Zaid M.A.A. and Dwekat A. (2021) 'The relationship between integrated reporting and corporate environmental performance: A green trial', Corp Soc Responsib Environ Manag., Vol. 28, 427-445.

19. Suchman, M.C. (1995) 'Managing legitimacy: Strategic and institutional approaches', Academy of Management Review, 20(3), 571-610.

20. Suttipun, M. (2017) 'The effect of integrated reporting on corporate financial performance: evidence from Thailand', Corporate Ownership and Control, 15(1), 133-142.

21. The International $<\mathrm{R}>$ Framework (2013) [Online]. Available at: https://integratedreporting.org/wp-content/uploads/2015/03/13-12-08-THE-INTERNATIONAL-IRFRAMEWORK-2-1.pdf (Accessed: 10 March 2021). 